\title{
REVIEW OF REGULATIONS GOVERNING SWITCHING DRUGS FROM RX TO OVER-THE-COUNTER IN THE USA, INDIA, AND EU
}

\author{
MEGHANA G*, SREE GREESHMA SWETHA K, RAVI KUMAR REDDY J, VENKATESWARA RAJU K \\ Department of Pharmaceutical Regulatory Affairs,Shri Vishnu College of Pharmacy (Autonomous), Vishnupur, Bhimavaram, Affiliated to \\ Andhra University, Visakhapatnam, Andhra Pradesh, India. Email: gollameghana1997@gmail.com
}

Received: 16 May 2021, Revised and Accepted: 21 July 2021

\section{ABSTRACT}

Rx to over-the-counter (OTC) switch is a data-driven, scientifically rigorous, and highly regulated process that allows consumers to have OTC access to a growing range of medicines. Patients often approach a pharmacist instead of a Healthcare Professional for minor illnesses such as fever, aches, nausea, allergies, cough, and cold. Switches are a logical extension for life-cycle management of a product to defense originator company from Generic competitors. The driving factors required for switching are self-diagnosis, self-medication, and self-administration. On increasing of Rx to OTC switching relatively rules and regulations governing are also improving. Label instructions have to be simple and easily understandable by ordinary people by preventing medication errors and drug abuse. Labeling must include indications, warnings, and directions for use especially since they are administered without medical guidance. Adding a graphic description on the label may be useful to patients, mostly illiterate individuals (e.g., Drug Facts Labeling). The advertisement may also influence patients' decisions on the selection of OTC products. Medicine advertisements should be closely monitored to ensure that they are truthful and are not misleading or unfair. In this respect, it is recommended that advertisements reflect the information that is contained in the product information leaflet, which, in turn, should be unbiased, evidence-based, and presented in a clear, understandable, and easily readable way. This article elaborates on regulatory requirements, challenges, and marketing aspects of Rx to OTC Switching medicinal products.

Keywords: Rx to Over-the-counter switch, Self-medication, Drug facts labeling, Advertisements, Indications.

(c) 2021 The Authors. Published by Innovare Academic Sciences Pvt Ltd. This is an open access article under the CC BY license (http://creativecommons.org/ licenses/by/4.0/) DOI: http://dx.doi.org/10.22159/ajpcr.2021v14i9.42393. Journal homepage: https://innovareacademics.in/journals/index.php/ajpcr

\section{INTRODUCTION}

Over-the-counter (OTC) drugs are generally disposed to consumers without a need for a prescription from a health-care provider. Most of the OTC drugs are approved by the regulatory agency containing ingredients that are safe and effective when used without physician concern [1]. In day-to-day life, common disorders such as frequent headaches, allergy, common cold, constipation, backache, acidity, and chronic fatigue can be medicated by OTC without consulting the healthcare provider. When drug manufacturers are prepared for switching their medications from prescription to OTC, three main factors must be considered such as benefit-risk comparison, consumer-friendly labeling, and how to consider the drug a right choice as an alternative to prescription medication [2]. Regulations detail the establishments where drugs may be sold, who is authorized to dispense them, and whether a prescription is required vary considerably from country to country. OTC medications have brand names and generic names similar to prescription medications [3].

In general, there are two categories of OTC medicines [4]:

I. The first category of OTC medicines is the one that has been under the class of non-prescription drugs from the time they were introduced

II. The second category of OTC medicines initially was prescription medicines but was later shifted to the OTC category.

According to the WHO, for a product to be an OTC medicine, it should be marketed on prescription for at least 5 years. The period for change of category from prescription drug to OTC varies from country to country [5].

\section{RATIONALE FOR RX-TO-OTC SWITCHES}

OTC drugs are available in the market without prescription and are widely used by consumers to treat minor ailments. The reasons for switching include extensive life-cycle management, increased defense strategy development against the generic competitor, and increasing consumer access to innovative OTC medications. Indeed, switching is also advantageous in consumer point in terms of less expensive than prescription drugs, decreased frequency of visits to physicians leading to lower health care costs, and an easy way of procuring drugs by the geriatric patients. The driving forces behind switches are diverse and multifactorial and depend on potential benefits implied by an individual switch for the various stakeholders affected [6]. Multiple economic analyses of Rx-to-OTC switches demonstrated entire cost savings to the health-care system by shifting parts of these costs "from the public purse to the private" $[7,8]$. In this way, upgrading self-support and amplifying consumer choice without compromising the consumer's safety and economic well-being are the guiding values for the switch evaluation process [9].

\section{DEFINITION OF RX TO OTC SWITCH}

Even though the definition varies from country to country, the Rx-toOTC switch refers to the transfer of proven prescription drugs (Rx) to nonprescription (OTC) status [10]. For a drug to be granted OTC status, it must have a wide safety margin and be useful and must bear understandable labeling to ensure proper use [11]. Many medications that are available as OTC today were previously labeled as prescription medications[12]. The drug's status is changed based on the drug's safety and information on the label describing the pros and cons of the drug product when it is used without a prescription from a health-care provider [13]. When nicotine replacement therapies (NRT) progressed to OTC, there was a $150-200 \%$ increase in their purchase in the $1^{\text {st }}$ year after the switch [14]. Critical barriers to switching include the potential for misuse and abuse of drugs, particularly for analgesics, and the resultant need to demonstrate safety and precise labeling to regulatory agencies [3]. 


\section{REASONS FOR A SHIFT OF DRUGS FROM THE PRESCRIPTION CATEGORY INTO THE OTC CATEGORY [15]}

Increasing health awareness [16]

There is an increasing mindset amongst the population concerning healthcare, which is towards wellness rather than treatment for illness because of a rising trend among people to keep themselves healthy.

\section{Expiration of product patents}

The expiration of a product patent is a strategy put in practice for those products whose patents have expired, especially in regulated markets, enabling the pharmaceutical company to extend the patented product's lifecycle.

\section{Repositioning strategy [17]}

This strategy is used to reposition those products that have reached the maturity stage of their product life cycle. When they are shifted into the OTC segment higher volume sales and revenues, due to higher market access are possible.

\section{Increase in population and demand}

Increasing population especially in urban areas, working couples leading to higher disposable incomes, fast-paced lifestyle, and the higher quantum of consulting fees, ease of availability, convenient dosage forms, and pack sizes have led to an increase in OTC usage.

The following sections include an overview of regulatory procedures in switching a prescription product to OTC status in countries - USA, India, and EU.

\section{SWITCHING PROCESS IN THE USA}

Before FDA considers a prescription drug product for reclassification to OTC status, the drug must meet specific criteria like Indications for which the product is to be used should be similar to its prescription indications and must permit easy diagnosis and monitoring by the patient [18]. The drug should have relatively low toxicity and a low potential for abuse. The prescription drug must prove safe and have 3-6 years of marketing [19]. There are mainly two regulatory pathways to bring a non-prescription medicine from prescription in the US, such as New Drug Application (NDA) process and OTC Drug Review (OTC Monograph) process [20]. An OTC monograph is a "rule book" for each therapeutic category containing active pharmaceutical ingredients, uses (indications), doses, labeling, and testing at which OTC drug is generally recognized as safe and effective, marketed irrelevant to NDA and FDA pre-market approval [21]. Non-prescription drug products sold under the OTC Drug Review are referred to as OTC monograph drugs [22].

The OTC Drug Review is a 3-phase rule-making process that establishes monographs. The other method for OTC approval in the NDA process is that manufacturers should submit appropriate data to the FDA for self-administration [23]. The data must include studies showing that labeling can be understood by consumers without healthcare providers. Under the NDA process, some drugs are approved directly as OTC drugs, but most are approved for a prescription before switching to OTC. This NDA involving OTC drugs are mainly handled by the "Division of Non-Prescription clinical development"[24]. The main differences between the NDA approval process and the OTC monograph process as shown in Table 1.

In case the FDA deems that the clinical data submitted along with the application is "sufficient to justify the OTC switch" [25] the sponsor can avail 3 years of marketing exclusivity under the Hatch Waxman Act when the results of the trials "have not been relied on already approved drugs to demonstrate substantial evidence of the effectiveness for any indication for a new patient population"[26]. There will be no requirement for OTC products' safety and efficacy data if there are no changes[27]. The entire process of switching takes nearly 10 months for the review process as shown in Fig. 1 [19]. In addition, the need for
Table 1: Differences between the NDA approval process and monograph process

\begin{tabular}{|c|c|}
\hline NDA Approval process & OTC Monograph process \\
\hline $\begin{array}{l}\text { Pre-market approval } \\
\text { - FDA reviews and } \\
\text { approves formulation } \\
\text { and labeling before } \\
\text { marketing. }\end{array}$ & $\begin{array}{l}\text { No pre-market approval because the FDA } \\
\text { proposes specific conditions for generally } \\
\text { recognized as safe and effective. In the } \\
\text { case of a developing monograph, it sets } \\
\text { forth conditions for continued marketing } \\
\text { pending a final monograph. Oversight } \\
\text { occurs on a post-marketing basis. }\end{array}$ \\
\hline Confidential filing & No confidential filing \\
\hline Drug-product specific & $\begin{array}{l}\text { Active ingredient-specific and evaluated } \\
\text { based on OTC drug category }\end{array}$ \\
\hline It may require a user fee. & No user fees \\
\hline $\begin{array}{l}\text { Exists marketing } \\
\text { exclusivity }\end{array}$ & No marketing exclusivity \\
\hline FDA evaluate timelines & $\begin{array}{l}\text { Manufacturers responsible for ensuring } \\
\text { a compliant product no requirement of } \\
\text { FDA-review (either pre-or post-market) }\end{array}$ \\
\hline $\begin{array}{l}\text { May require clinical } \\
\text { studies, including studies } \\
\text { on label comprehension, } \\
\text { self-selection, and actual } \\
\text { use }\end{array}$ & $\begin{array}{l}\text { Generally, does not require clinical } \\
\text { studies. Label comprehension and } \\
\text { actual use studies are not required for } \\
\text { ingredients already present in a final or } \\
\text { tentative final monograph }\end{array}$ \\
\hline $\begin{array}{l}\text { Approved labeling is } \\
\text { unique to the drug }\end{array}$ & $\begin{array}{l}\text { The monograph defines labeling. After } \\
\text { marketing, the FDA can review the } \\
\text { finalized labeling at any time to determine } \\
\text { whether it is truthful or misleading }\end{array}$ \\
\hline $\begin{array}{l}\text { Approved NDA refers to } \\
\text { the "license" to market }\end{array}$ & $\begin{array}{l}\text { A final monograph is open access to } \\
\text { everyone }\end{array}$ \\
\hline $\begin{array}{l}\text { Trade name reviewed } \\
\text { before marketing }\end{array}$ & $\begin{array}{l}\text { No review of trade name before } \\
\text { marketing. Once marketed, the FDA can } \\
\text { review the trade name at any time }\end{array}$ \\
\hline
\end{tabular}

OTC: Over-the-counter

sponsors to submit additional data that support the use of the drug in the OTC status. Thus, consumer behavior studies are of the following types[28]:

\section{Label comprehension studies}

Label comprehension studies are those where the subjects are not administered any drug. In lieu, subjects are provided with an OTC label that coheres to a prerequisite format (called a "Drug Facts label"). These studies are used to know whether layman understands drugs based on a label.

\section{Self-selection studies $[29,30]$}

These studies are designed to test if consumers can predict the information acquired from the OTC label to their individual medical history and make correct self-imposed decisions, that is, decide whether the OTC drug is safe for them to use.

\section{Actual use studies}

Actual use studies are designed to mimic actual OTC use of the product to determine whether the consumer safely and effectively uses the drug after the correct self-selection. These studies also confirm that the product cannot be abused or misused by the consumer.

Depending on the product, human factors studies may also be required to indicate that the consumer can adequately interact with the product.

\section{Case history: Rx-To-0TC switch of Voltairean arthritis pain}

Diclofenac sodium is an active ingredient in Voltairean arthritis pain, clinically proven to rely upon joint pain due to arthritis [31]. This switching process includes the study of 12 weeks, randomized, double-blind, multigenre, vehicle-controlled, and parallel-group study of diclofenac sodium gel $1 \%$ in 492 adults aged $\geq 35$ years with osteoarthritis [32]. It targets pain directly at the site[33]. The amount of diclofenac sodium that is systemically absorbed from voltairean 
arthritis pain is, on average, $6 \%$ of the systemic exposure from an oral form of diclofenac sodium [34]. Voltairean arthritis pain will be available on US shelves in Spring 2020 [35]. This Voltairean product was first approved as a prescription drug by the FDA in 2007 to relieve osteoarthritis pains of joints in the hands, knees, and feet [36].

The switching of Rx to OTC drugs sales [37] and the number of drugs switching [38] are being increased in the USA from year to year as shown in Fig. 2.

\section{SWITCHING PROCESS IN INDIA}

The pharmacist sells OTC drugs without a prescription from a health care professional. In India, the regulatory regime is gray, primarily because OTC's term has not been defined under the Drugs and Cosmetics Act 1940 (D\&C Act) and the Drugs and Cosmetics Rules 1945 (D\&C Rules) [39]. The key factors driving the growth of the Indian OTC drugs market are the shift in consumer attitude toward self-medication, product alterations, and the Propensity of pharmaceutical companies toward OTC drugs from prescription (RX) drugs[40].

Apart from these regulations, OTC products can be categorized into

a. True OTC products introduced in the marketplace and advertised on public media

b. Prescription products converted into OTC

c. Rx products that are purchased OTC-OTx products.

Since in India, the ratio of doctor to patient is abysmally low, there are more possibilities to switch to OTC [41]. An analytical interpretation of various data places focuses on vitamins, cough \& cold, antacids, antipyretic, and NSAIDs as an opportunity area for India's switch [42].

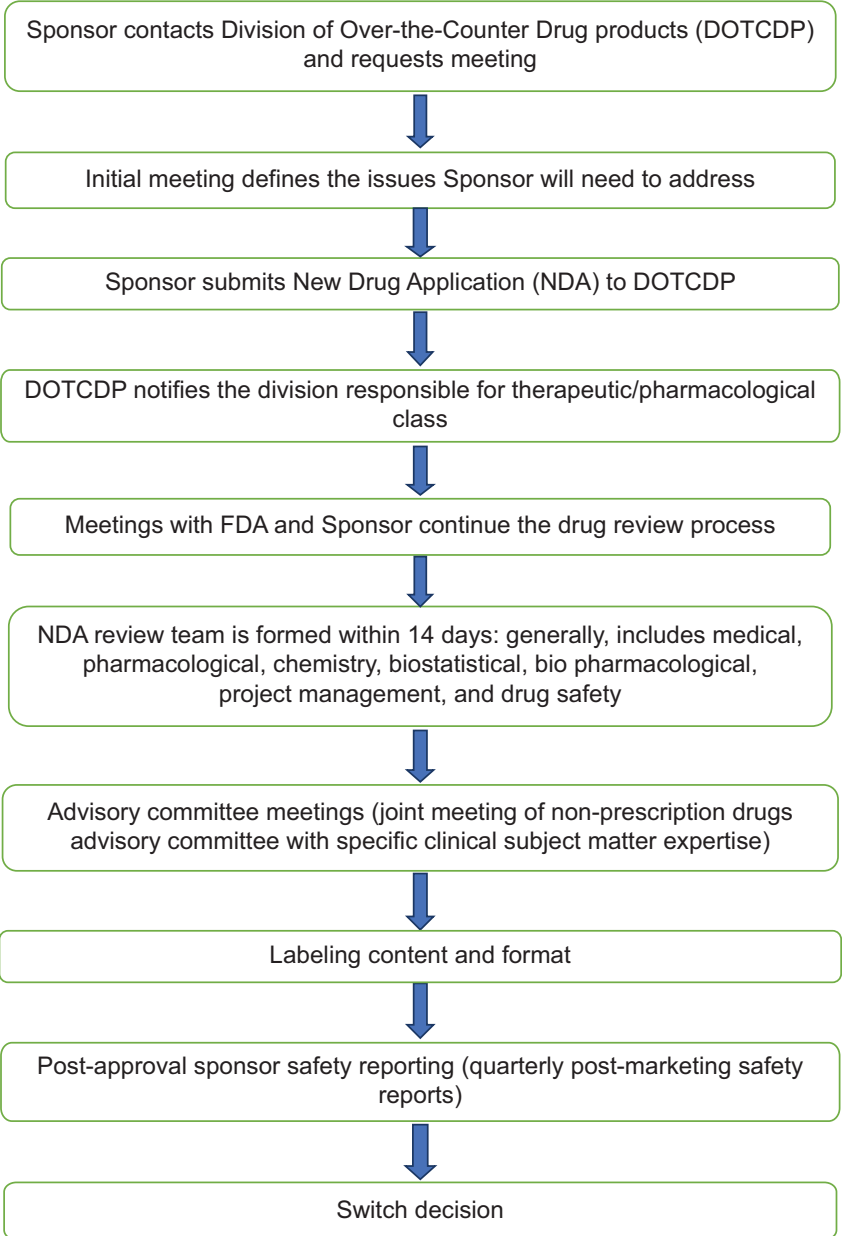

Fig. 1: Switching process from Rx to over-the-counter in the USA
Since there are no stringent regulations followed for switching, there is a need for the hour, and advertisements may be legally allowed once a separate OTC category is recognized [43].

Labeling is of primary importance in OTC medicinal products. It conveys crucial drug information to the consumers, and the information provided should be readable. Labeling must comply with the specifications as per Rule 95 of the Drugs and Cosmetic act [44]. Apart from the advertisement norms and definition, the current changes will include the OTC drug's essential characteristics and classification into OTC-1 and OTC- 2 based on safety, therapeutic index, need for accessibility to patient, availability, non-addictive nature, supply chain mechanism, and socio-demographic conditions of the country [45]. Number of Rx to OTC switches from 2011 to 2020 as shown in Fig 3.

At present, there are some regulations provided for Rx to OTC switching in India as shown in Table 2 [46].

\section{Reasons for failure in OTC switch}

Failure with the OTC switch can be influenced by a few common factors, either individually or in combination with no prior pharmacy training or education programs before the OTC switch. There is no visible or outward sign of symptoms or problems occurring from the condition [6]

\section{Case history: Rx to OTC switch of allegra}

Allegra contains Fexofenadine $\mathrm{HCl}$ as a medicinal ingredient shown to inhibit the H1-mediated effect of injected histamine in producing skin wheal and flare in a dose-dependent manner, with the $40 \mathrm{mg}$ bid dose being the minimum effective dose [47]. Four randomized, double-blind, placebo-controlled multisite studies were conducted in subjects with seasonal allergic rhinitis. In three trials, fexofenadine hydrochloride $60 \mathrm{mg}$ twice daily significantly reduced total symptoms compared to placebo [48]. A statistically significant reduction in symptoms was observed after the first $60 \mathrm{mg}$ dose, with the effect maintained all over the 12-h interval. The onset of action for reduction in total symptoms, excluding nasal congestion, was observed at $60 \mathrm{~min}$ after a single $60 \mathrm{mg}$ or $120 \mathrm{mg}$ dose of fexofenadine $\mathrm{HCl}$ administered to subjects suffering from ragweed pollen allergy, in contrast to $100 \mathrm{~min}$ for placebo when exposed to this allergen in an environmental exposure unit.

In a 4-week, multicenter, randomized, double-blind, and placebocontrolled trial in patients include 12-78 years of age with perennial allergic rhinitis $(\mathrm{n}=668)$, fexofenadine $60 \mathrm{mg}$ bid significantly reduced total symptom compared to placebo. A statistically, significant efficacy was maintained throughout the 12-h treatment interval. No evidence of carcinogenicity was observed. Finally, allegra was switched to OTC on January 25, $2011[49,50]$

OTC drugs commonly belong to NSAIDs, Anti-allergy, Vitamins and supplements, Gastrointestinal, and medicated dermatological products. Significant switches are mostly done in Analgesics, accounting for substantial sales of $33 \%$ as shown in Fig. 4 [51].

\section{SWITCHING PROCESS IN EU}

Article 70 of Directive 2001/83/EC provides two classifications for the supply of medicinal products for human use, such as "medicinal

\section{Table 2: Current regulation for OTC products in India}

\begin{tabular}{|c|c|}
\hline $\begin{array}{l}\text { Legal } \\
\text { recognition }\end{array}$ & $\begin{array}{l}\text { No distinct legal recognition. Products out schedule } \\
\mathrm{H}, \mathrm{G}, \mathrm{X} \text { (prescription not mandatory but mandatory } \\
\text { labeling requirement) and products included under } \\
\text { schedule K considered non-prescription }\end{array}$ \\
\hline $\begin{array}{l}\text { Drug } \\
\text { registration }\end{array}$ & $\begin{array}{l}\text { The product has to be an approved prescription, } \\
\text { followed by an application for the switch to OTC }\end{array}$ \\
\hline $\begin{array}{l}\text { Criteria for } \\
\text { acceptance }\end{array}$ & $\begin{array}{l}\text { Stability data for three validation batches of good } \\
\text { manufacturing practices certified plant }\end{array}$ \\
\hline
\end{tabular}

OTC: Over-the-counter 


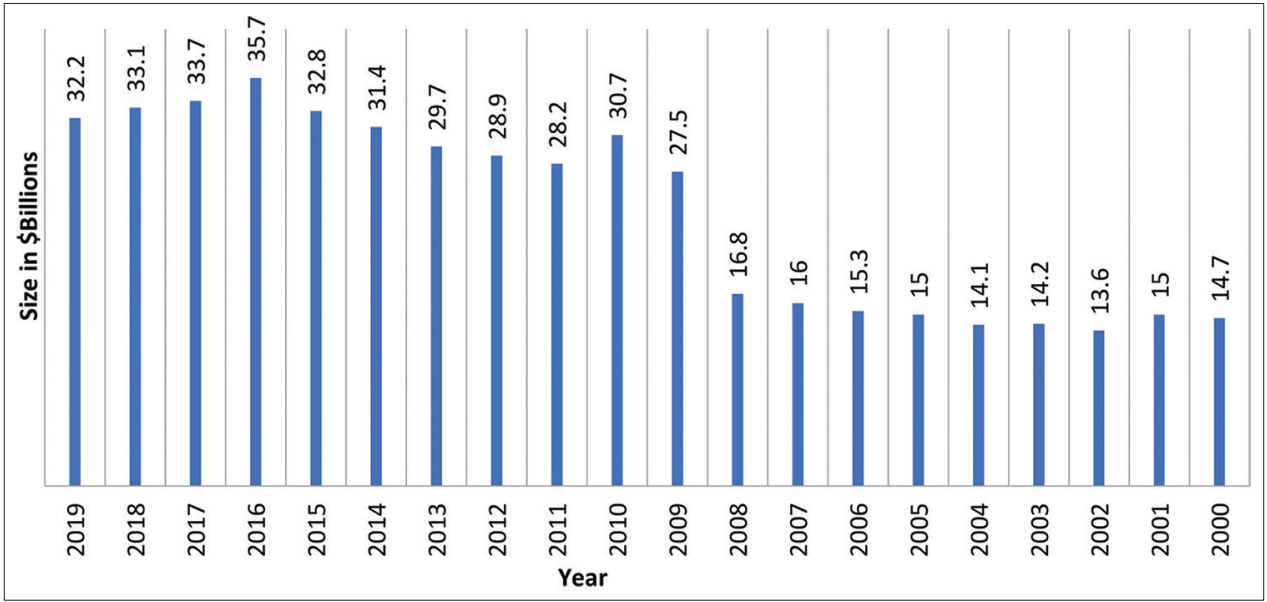

Fig. 2:Over-the-counter sales in the USA from 2000 to 2019

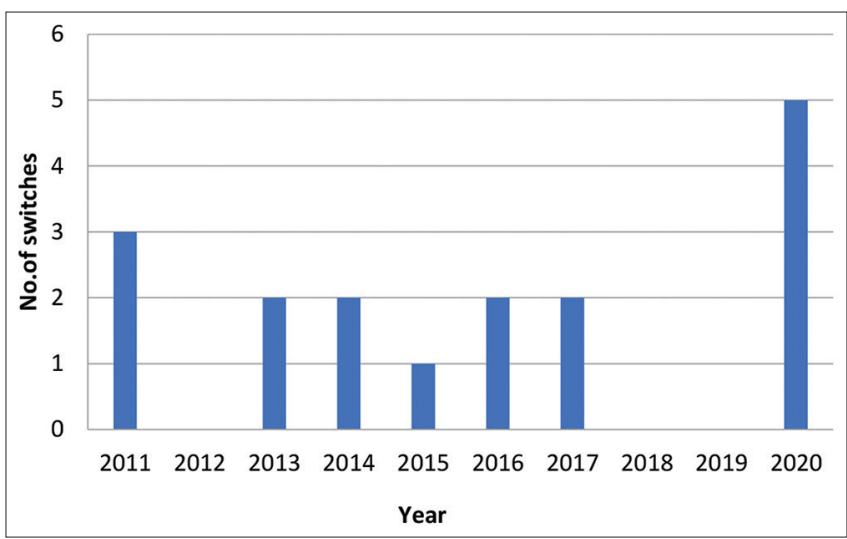

Fig. 3: Number of Rx to OTC switches from 2011 to 2020

products not accountable to medical prescription" and "medicinal products accountable to medical prescription" [52]. For a prescription product to switch to OTC, the prescription drug must have already been in the market for 5 years [53]. There are multiple regulatory pathways available for changing legal status depending on the initial approval process, that is, national procedure, centralized, and decentralized procedure. Classification of medicines is a core competency of federal health authorities [54]. Therefore, the final decision about OTC products category into pharmacy-only or General Sale Medicines (GSL) drugs is taken by individual member states[55].

For instance, in the United Kingdom, consumers have been familiar with GSL medicines, and many feel comfortable making decisions about their health and the medication they need. In Ireland, GSL medications have also been available for a relatively long time, and consumers are used to this product type. The UK stands out as incredibly proactive in encouraging switch considerations [4].

Recently amended Regulation (EU) 2019/834 of the European Parliament on May 20, 2019, amending Regulation (EU) No 648/2012 for clearing obligation, to minimize the compliance burden on small financial and nonfinancial counterparties, clearing transparency in cost issues [56,57].

\section{DATA REQUIREMENTS ARE AS FOLLOWS [58]}

\section{Nonclinical and clinical overview (expert reports)}

The expert should provide a critical analysis report of the product's proposed availability without a medical prescription with the dose and indications. This section has to be prepared in common technical document format.

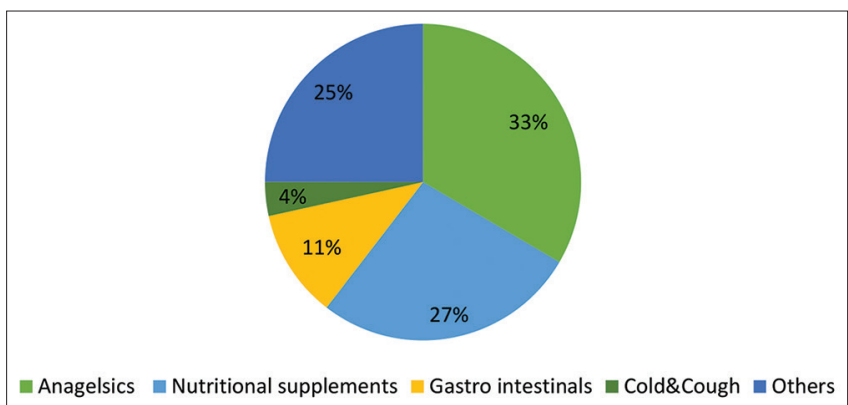

Fig. 4: Categorization of over-the-counter drugs as per the general indication

Nonclinical and clinical safety information [59]

This section includes summaries of animal studies or humans studies that show low general toxicity and no reproductive toxicity, genotypic, or carcinogenic effects pertinent to the medicinal product's experience/ exposure.

\section{Clinical efficacy}

It is generally not considered in changing the medicinal product classification unless the switched product includes changes in indications or posology.

\section{Product information}

For a prescription medicinal product switched to a non-prescription medicinal product, the proposed labeling and package leaflet are essential elements of the application. Non-prescription medicinal products will be closely examined for comprehensive information and effectiveness in protecting patients from safety hazards. For the nonprescription medicinal product with no outer packaging or the outer carton, the immediate packaging should include instructions for use as required by Article 54 of Directive 2001/83/EEC.

\section{Case history: Rx to OTC switch of NRT [60]}

The European Region of the World Health Organization (WHO), with $15 \%$ of the world's population, faces practically one-third of tobaccorelated diseases. Nicotine is by far the most potent behaviorally active compound present in tobacco smoke [61]. There is considerable evidence to suggest that most people who smoke tobacco do so to experience its pleasant psychopharmacological properties. Nowadays, NRT is available for self-medication in almost all European Countries [62]. NRT has been extensively tested in controlled clinical trials during the past 20 years and has been demonstrated to reduce 
Table 3: A brief comparision of Rx to OTC switches in USA,India and EU

\begin{tabular}{|c|c|c|c|c|}
\hline S. NO & Key point considerations & USA & India & EU \\
\hline 1. & Regulatory body & $\begin{array}{l}\text { US FDA, Mainly OTC, are reviewed } \\
\text { under CDER'S office of non- } \\
\text { prescription drugs }\end{array}$ & Drugs and Cosmetic act (1940) & $\begin{array}{l}\text { Article } 70 \text { of Directive } \\
\text { 2001/83/EC. }\end{array}$ \\
\hline 2. & OTC Monograph & $\begin{array}{l}\text { The Division of Non-prescription } \\
\text { Regulation Development }\end{array}$ & NA & NA \\
\hline 3. & Label decision-making & Drug fact labeling 21CFR 201.66(d) & $\begin{array}{l}\text { Rule } 95 \text { of the Drugs and } \\
\text { cosmetic act }\end{array}$ & $\begin{array}{l}\text { Articles 54-69 of Directive } \\
\text { 2001/83/EC }\end{array}$ \\
\hline 4. & Advertisement & Federal trade commission & Magic remedies act 1954 & $\begin{array}{l}\text { Article } 88 \text { of the Directive } \\
\text { 2001/83/EC }\end{array}$ \\
\hline 5. & Distribution & Supermarket & $\begin{array}{l}\text { Generally, a small independent } \\
\text { shop }\end{array}$ & $\begin{array}{l}\text { Supermarket/even at a fuel } \\
\text { station }\end{array}$ \\
\hline 6. & Switch RX to OTC & Drug review panel & Lacks SUCH System & Directive 2004/27/EC \\
\hline 7. & Price control & NA & DPCO 1995 & $\begin{array}{l}\text { 89/105/EEC(Transparency } \\
\text { directive) }\end{array}$ \\
\hline 8. & $\begin{array}{l}\text { Marketing exclusivity } \\
\text { period }\end{array}$ & 3 years & Not Yet defined & 1 year \\
\hline 9. & $\begin{array}{l}\text { Serious adverse events } \\
\text { Reporting }\end{array}$ & 15 Calendar days & $\begin{array}{l}\text { The investigator shall report } \\
\text { all SAE to sponsorin } 24 \mathrm{~h} \text { to the } \\
\text { ethics committee within seven } \\
\text { working days }\end{array}$ & 15 Calendar days \\
\hline 10. & $\begin{array}{l}\text { The period required for } \mathrm{Rx} \\
\text { products to be marketed } \\
\text { before switching }\end{array}$ & $3-5$ years & 5 years & 3 years \\
\hline
\end{tabular}

OTC: Over-the-counter

desire and tobacco withdrawal symptoms. Since medicinal products are available for this indication, it could be considered a comparatorcontrolled parallel-group design. The trial duration will be 12 months, with treatment during the first 6-12 weeks. In case more extended treatment duration is necessary, this should be justified, and the offtreatment period should be at least 6 months. A brief comparision of Rx to OTC switches in USA,India and EU as shown in Table 3.

\section{MECHANISM OF RX TO OTC SWITCH [5]}

Before switching the medicinal product from $\mathrm{Rx}$ to OTC status, the sponsor must check whether the product falls within the domain of OTCness. For example, switching extremely toxic chemotherapeutic drugs and drugs for rare diseases (orphan drugs) certainly has unfruitful results. In general, the product must possess the following characteristics.

1. The sales volume is high during the marketing period of prescription medicinal products, that is, the product is enormously used by consumers

2. This product has been marketed in the previous $\mathrm{Rx}$ status for a sufficient number of years and the period varies from country to country

3. The post-marketing surveillance data shows no serious adverse events during the marketing period, that is, after the product is approved in the market.

While approving a $\mathrm{Rx}$ to OTC switch, regulators may also require specific changes from the previous $\mathrm{Rx}$ version such as restrictions in pack sizes, restrictions in the approved indications for the OTC version, changes in the label of layman's friendly format [63].

Factors influencing a decision to proceed with switch [6]

- The active substance is suitable as a self-medication candidate

- The active substance is going to be first in a Rx category to switch (creating a new OTC category) [64]

- Once the prescription medicinal product is switched to a nonprescription medicinal product, there is the availability of exclusivity

- The product is having a recognizable difference concerning existing treatments

- The product has the potential for modification into different dosage forms to increase differentiation.

\section{Challenges to regulatory authorities while switching}

During switching from RX to OTC, regulatory authorities' primary challenge is to balance between benefits of a choice of medications for self-treatment and potential risks on account of unsuitable use. There is an obvious need to create new research tools to support regulatory decision-making with an increase in complex switches [65]. There are multiple countries involved in single unions thereby issues occur since different cultural challenges arise. For example, the EU has 27 countries that have different challenges. Finally, the necessity of multiple stakeholder involvement and close industry cooperation within the switching process is likely to contribute to a constant improvement of the drug approval process, simultaneously complying with the industry's desire for maximal consistency and transparency [19].

\section{REGION-WISE OUTLOOK OF RX-TO-OTC SWITCHES MARKET GLOBALLY}

North America is foreseen to show the highest revenue growth and cling to the largest market shares in the global Rx-to-OTC Switches market due to modern health-care infrastructure and medical costs. In addition, increasing the acceptance rate and requirement will boost the Rx-to-OTC Switches market in this region, followed by Europe [66]. The Rx-to-OTC Switches market in the Asia-Pacific region is expected to register moderate growth due to low acceptance and not exercising a proper caution rate for mental disorders and depression [67]. Latin America, Middle East, and Africa are expected to show stagnant Rxto-OTC Switches market growth due to weak healthcare management for mental illness, depression, anxiety-related disorders, and low awareness [68]. The OTC drugs market in China is the second biggest globally, accounting for over $20 \%$ of the global OTC drugs market [69].

The global OTC drug market was assessed at USD 141.6 billion in 2018, and it is anticipated to grow with a CAGR of $7.6 \%$ over the forecast period of 2019-2025 [70].

The OTC drugs market's key players support significant product brand fairness during their patent period to improve sales and revenue [71]. Moreover, the growing trend of self-medication among the population is also putting up the ever-growing demand for OTC drugs in the EU. The performance of OTC sales across different countries is shown in Fig. 5 [70]. 


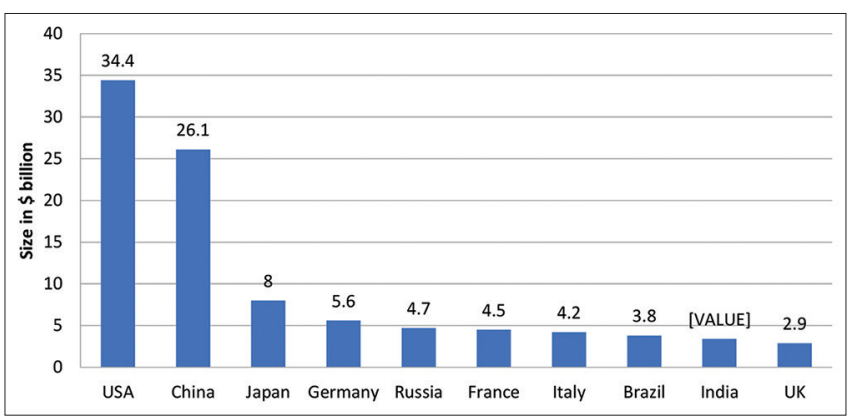

Fig. 5: Performance of top 10 markets till 2020

\section{CONCLUSION}

The definition of drugs amendable to OTCness is continuously evolving. In the case of the US and EU, full-fledged regulations relating to switching have been framed. Whereas in India, OTC's regulations are being framed by the Drugs and Cosmetic act 1940 and Drugs and Cosmetic rules 1945. The factors influencing Rx's switching to OTC products include increasing globalization, shrinking new product pipeline, and the rising cost of new drug discovery, for life-cycle extension of off-patent drug manufacturers. This Rx to OTC switching process immensely improves consumers' health. This switching process is also advantageous to manufactures in regaining the lost revenue during the prescription sales. Although switching is advantageous in many aspects, there is a requirement of understanding labels to patients. If label instructions are not crystal clear to consumers, there are chances of adverse effects and drug interactions. Hence, pharmaceutical companies that wish to initiate OTC switches must also ensure that consumers are enlightened about the label's information. Other key drivers for switching to the OTC phenomenon include increased access to patients (convenience) and the potential to provide more accessible treatment to the previous non-treaters who do not visit doctors. Ultimately, the switching process is significantly beneficial to drug manufacturers, consumers in terms of profits in sales, treatment of minor illnesses, increasing innovations, and cost-effective OTC medicinal products.

\section{ACKNOWLEDGMENT}

The authors gratefully acknowledge the constant encouragement and support provided by the management of Shri Vishnu College of Pharmacy, Vishnupur, Bhimavaram, Andhra Pradesh.

\section{AUTHORS' CONTRIBUTION}

All authors have contributed to the preparation of the manuscript.

\section{CONFLICTS OF INTEREST}

The authors declare that there are no conflicts of interest.

\section{AUTHORS' FUNDING}

Nil.

\section{REFERENCES}

1. Barbara A. Levey Over-the-counter Medications. United States: MedlinePlus; 2021. p. 1221-4. Available from: https://www. sciencedirect.com/science/article/pii/B9781416032915500913;2009. [Last accessed on $2021 \mathrm{Jul}$ 02]

2. Chang J, Lizer A, Patel I, Bhatia D,Tan X, Balkrishnan R, et al. Prescription to over-the-counter switches in the United States.J Res Pharm Pract 2016;5:149-54.

3. Over-the-counterdrug; 2020. Available from: https://www.en.wikipedia. org/wiki/Over-thecounterdrugs.

4. Marathe PA, Kamat SK, Tripathi RK, Raut SB, Khatri NP. Over-thecounter medicines: Global perspective and Indian scenario.J Postgrad Med 2020;66:28-34.
5. Kartha S, Kulyadi G, Bhat K, Sathyanarayana M. Switching drugs from Rx to OTC Status-a regulatory perspective.J Young Pharm 2020;9:3-7.

6. Sengupta G, Rein AM. Rx-to-OTC Switches: Growth, Drivers and the Role of Patients-Lubrizol; 2021. Available from: https://www.lubrizol. com/Health/Blog/2020/11/Rx-to-OTC-Switches.

7. Otto MH, Pillarella C. The economic impact of a switch from prescription-only to non-prescription drugs in Italy. Front Pharmacol 2018;9:1069.

8. Cohen J, Millier A, Karray S, Toumi M. Assessing the economic impact of Rx-to-OTC switches: Systematic review and guidelines for future development.J Med Econ 2013;16:835-44.

9. Available from: https://www.ozpharmagroup.com/ data/docs/ whitepaper_otc $\% 20$ switch $\% 20$ as $\% 20$ patent $\% 20$ extension_final $\% 202$. pdf. [Last accessed on $2021 \mathrm{Jul} 03$ ].

10. Rx-To-OTC Switch Consumer Healthcare Products Association. Available from:https://www.chpa.org/our-issues/otc-medicines/rx-otcswitch.

11. Rx to OTC Switch-a Case Study of Benadryl. NCK Pharma. Available from: https://www.nckpharma.com/rx-to-otc-switch-case-study-ofbenadryl/,2015.

12. More Than 100 OTC Ingredients Strengths or Indications Are on the Market Today. Course Hero. Available from: https://www.coursehero. com/file/62210847/module-2docx. [Last accessed on 2021 Jul 1].

13. Available from: https://www.researchonline.ljmu.ac.uk/id/ eprint $/ 11064 / 3 / \mathrm{Paw}$ ar $\% 20$ et $\% 20$ a $1 \% 20$ Supplementary $\% 20$ Information $\% 20-\% 20$ Details $\% 20$ of $\% 20$ Databases.xlsx.

14. Available from: https://www.ozpharmagroup.com/_data/docs. [Last Accessed on 2021 Jun 29].

15. Home. Consumer Healthcare Products Association. Available from: https://www.chpa.org/about-chpa. [Last accessed on 2021 May 28].

16. Edington DW, Schultz AB, Pitts JS. The future of health promotion in the $21^{\text {st }}$ century. Am J Lifestyle Med 2016;10:242-52.

17. Kakkar AK. Patent cliff mitigation strategies: Giving new life to blockbusters. Expert Opin Ther Pat 2015;25:1353-9.

18. Over-the-counter Otc Medication: Topics; 2021. Available from: https://www.worldwidescience.org/topicpages/o/over-thecounter+otc+medication.html. [Last accessed on 2021 Jul 02].

19. U.S. Food and Drug Administration. Prescription to Over-the-counter (OTC) Switch List, FDA; 2020. Available from: https://www.fda.gov/ about-fda/center-drug-evaluation-and-research-cder/prescription-overcounter-otc-switch-list. [Last accessed on 2021 May 25].

20. Modernizing FDA's Regulation of Over-the-counter Drugs; 2017. p. 115-55. Available from: https://www.govinfo.gov/content/pkg/ CHRG-115hhrg27228/html/CHRG115hhrg27228.htm.

21. FDA OTC Glossary; 2021. Available from: https://www.accessdata. fda.gov/scripts/cder/training/otc/topic3/images/Glossary.pdf. [Last accessed on 2021 Jun 28].

22. Deshpande G, Srivastava R. A Comparative Study to Identify the OTC Brand Preference in The Antacid Segment and The Influencing Factors for Consumer Purchase; 2018. Available from: https://www. Semanticscholar.org,ijipsr. [Last accessed on 2021 Jun 25].

23. Over-the-counter (OTC) Drug Monograph Process. U.S. Food and Drug Administration; 2021. Available from: https://www.fda.gov/ drugs/over-counter-otc-drug-monograph-process. [Last accessed on 2021 Jun 23].

24. Over-the-counter (OTC) Drug Review. OTC Monograph Reform in the CARES Act US FDA. Available from: https://www.fda.gov/drugs/ over-counter-otc-nonprescription-drugs/over-counter-otc-drug-reviewotc-monograph-reform-cares-act. [Last accessed on 2021 Jul 03].

25. Now Available Without a Prescription, U.S. Food and Drug Administration. Available from: https://www.fda.gov/drugs/ information-consumers-and-patients-drugs/now-available-withoutprescription. [Last accessed on 2021 Jul 04].

26. Kartha SS, Kulyadi GP, Bhat K. Switching drugs from Rx to OTC status-a regulatory perspective and drugs from Rx to OTC status a regulatory perspective.J Young Pharm 2017;9:3-7.

27. Available from: https://www.digitalcommons.uri.edu/cgi/viewcontent. cgi?referer $=\&$ httpsredir $=1 \&$ article $=1434 \&$ context $=0$ a_diss. [Last accessed on 2021 Jun 22].

28. Rx-to-OTC Switch: Expanding to the US Over-the-Counter Market. Camargo; 2017. Available from: https://www.camargopharma.com/ resources/blog/rx-to-otc-switch-expanding-to-the-us-over-the-countermarket. [Last accessed on 2017 Jun 29].

29. Self-selection Studies for Nonprescription Drug Products. U.S. Food and Drug Administration; 2020. Available from: https://www.fda.gov/ regulatory-information/search-fda-guidance-documents/self-selectionstudies-nonprescription-drug-products. [Last accessed on 2021 Jun 26]. 
30. Catlin JR, Brass EP. The effectiveness of nonprescription drug labels in the united states: Insights from recent research and opportunities for the future. Pharmacy (Basel) 2018;6:119

31. Regulatory Mechanisms for Marketing OTC Drug Products. U.S. Food and Drug Administration. Available from: https://www.fda.gov/about$\mathrm{fda} /$ center-drug-evaluation-and-research-cder/regulatory-mechanismsmarketing-otc-drug-products2020. [Last accessed on 2021 Jun 25].

32. Guidance for Industry Label Comprehension Studies for Nonprescription Drug Products U.S. Department of Health and Human Services Food and Drug Administration, Center for Drug Evaluation and Research (CDER). Available from: https://www.fda.gov/ regulatory-information/search-fda-guidance-documents/labelcomprehension-studies-nonprescription-drug-products,2018. [last accessed on 2021 Jun 24].

33. Voltaren Gel Now. Available from: https://www.goodrx.com/blog/ voltaren-gel-available-otc2020. [Last Accessed on 2021 Jun 23].

34. Healthcare G. Voltaren Arthritis Pain Gel Empowers Early Morning Risers Living with Osteoarthritis; 2021. Available from: https://Www.Prnewswire.Com/News-Releases/VoltarenArthritis-Pain-Gel-Empowers-Early-Morning-Risers-Living-WithOsteoarthritis-301282039.Html. [Last accessed on 2021 May 29].

35. OTC Sales in the USA From 2000-2019. Available from: https://www. statista.com/statistics/307237/otc-sales-intheus/\#: :text=For\%20 $2019 \% 2$ C $\% 20$ it $\% 20$ is $\% 20$ estimated,around $\% 2032.2 \% 20$ billion $\% 20$ U.S.\%20dollars. [Last accessed on $2021 \mathrm{Jul} 01$ ].

36. Graph of no. of Switches From 2011-2020. Available from: https:// www.fda.gov/about-fda/center-drug-evaluation-and-researchcder/prescription-over-counter-otc-switch-list. [Last accessed on 2021 Jun 01].

37. NCK Pharma. Case Study: Rx-to-OTC Switch of Voltaren Arthritis Pain.Karnataka: NCK Pharma; 2020.

38. Voltaren:A Case Study in the US. Knee Efficacy; 2020. Available from: https://www.Gskhealthpartner.com.

39. India Corporate Law. Over the Counter Drugs-regulatory Clarity on the Horizon. India: India Corporate Law; 2020.

40. Wire B. Global Pet Wearable Market (2020 To 2025)-industry Trends, Share, Size, Growth, Opportunity and Forecast; 2020. Available from: https://www.Researchandmarkets.Com. [Last accessed 2021 Jun 24].

41. India's Doctor-patient Ratio Still Behind WHO-prescribed 1:1,000: Government. Business; 2021. Available from: https://www.businessstandard.com/article/pti-stories/doctor-patient-ratio-in-india-less-thanwho-prescribed-norm-of-1-1000-govt-119111901421 1.html. [Last accessed on 2021 Jun 23].

42. Pharma Formulators Diverge on Strategy for Non-prescription Businesses: IndRa Report Pharma Formulators Diverge on Strategy for Non-prescription Businesses: India Report-Express Pharma. Express Pharma. Available from: https://www.expresspharma.in/managementpharma/pharma-formulators-diverge-on-strategy-for-non-prescriptionbusinesses-india-ratings-and-research-report. [Last accessed on $2021 \mathrm{Jul}$ 04]

43. Government to Announce Regulatory Guidelines for OTC Drugs: Dy Drug Controller, MoH\&FW Express Pharma; 2021. Available from: https://www.expresspharma.in/govt-to-announce-regulatoryguidelines-for-otc-drugs-dy-drug-controller-mohfw. [Last accessed on 2021 Jun 26].

44. OPPI Seeks Deregulation of Pricing and Promotion of OTC Drugs. Available from: http://www.pharmabiz.com/2018. [Last accessed 2018 Jun 30].

45. News B, News I, Soon G. Government to Come Up with List of Over-the-counter Drugs Soon-Times of India. The Times of India; 2021. Available from: https://www.timesofindia.indiatimes.com/ business/india-business/govt-to-come-up-with-list-of-otc-drugs-soon/ articleshow/71268127.cms. [Last accessed on 2021 Jun 24].

46. Shankara R, Joshi M, Pathakc K. Labeling of OTC Drugs in India: Dilemma whether pharmacy centred or patient-centered. Indian J Pharm Pract 2016;9:199-203. Available from: https://www.researchgate. net/publication/309730845_Labeling_of_OTC_Drugs_in_India Dilemma Whether Pharmacy Centred or Patient Centre $\overline{-}{ }_{-}^{-}$[Last accessed on 2021 Jun 30].

47. Axelrod D, Bielory L. Fexofenadine hydrochloride in the treatment of allergic disease:A review.J Asthma Allergy 2008;1:19-29. Available from: https://www.ncbi.nlm.nih.gov/pmc/articles/PMC3121339/. [Last accessed on $2021 \mathrm{Jul} 01]$.

48. Juniper EF. Comparison of the efficacy, safety and quality of life provided by fexofenadine hydrochloride $120 \mathrm{mg}$, loratadine $10 \mathrm{mg}$ and placebo administered once daily for the treatment of seasonal allergic
rhinitis.Clin Exp Allergy 2000;30:891-9.

49. Available from: https://www.malacards.org/card/allergic rhinitis?showAll=True. [Last accessed on 2021 Jun 21].

50. EudraLex. Pharmaceutical Legislation for Medicinal Products for Human Use. Vol. 1. European: EudraLex; 2015. Available from: https:// www.ema.europa.eu/en/documents/regulatory-procedural-guideline/ directive-2001/83/ec-european-parliament-council-6-november-2001community-code-relating-medicinal-products-human-use_en.pdf. [Last accessed on 2021 Jun 21].

51. European Medicines Agency pre-authorisation Procedural Advice for Users of the Centralised Procedure. Available from: https:// www.ema.europa.eu/en/documents/regulatory-procedural-guideline/ european-medicines-agency-pre-authorisation-procedural-adviceusers-centralised-procedure_en-0.pdf,821278/2015. [Last accessed on 2021 Jun 30].

52. COVID-19 Response: Summer; 2021. Available from: https:// www.assets.publishing.service.gov.uk/government/uploads/system/ uploads/attachment_data/file/949105/reclassification_guideline_ for_20210101__final.pdf. [last accessed on 2021 Jul 04].

53. European Market Infrastructure Regulation. Available from: https:// www.En.wikipedia.org.2020. [Last accessed on $2021 \mathrm{Jul}$ 02].

54. EMIR 2020-21 Update: REFIT, Benchmarks, Brexit, and Beyond. JD Supra; 2021. Available from: https://www.jdsupra.com/legalnews/ emir-2020-21-update-refit-benchmarks-2828900. [Last accessed on 2021 Jun 20].

55. Available from: https://www.hpra.ie/docs/default-source/publicationsforms/guidance-documents/aut-g0070-guide to_reclassification (switching) of legal supply status for human medicinal products-v4.pdf? $\overline{s f v r s n}=\overline{34}$. [Last accessed on 2021 Jun 29].

56. Raja BM, Rao KR. Regulatory and Clinical Requirements for Prescription to Otc Switches in us and India. Available from: https:// www.regulatory-and-clinical-requirements-for-prescription-tootc-switches-in-usa-and-india-13600-prdad. [Last accessed on 2021 Jun 28].

57. Scientific Guidelines; 2020. Available from: https://www.ema. europa.eu/en/documents/scientific-guideline/guideline-developmentmedicinal-products-treatment-smoking_en.pdf. [Last accessed on 2021 Jul 02]

58. Morck H. Rx-to-OTC Switch and the Provision of Data Exclusivity in Europe-specification and Elaboration of Eligibility Criteria Based on a Status Quo Analysis; 2021. Available from: https://www.d-nb. info/1044395648/34

59. How are Disparities in Smoking Highlighting the Global Issue of Health Inequality?Tobacco; 2021. Available from: https://www.who.int/newsroom/fact-sheets/detail/tobacco. [Last accessed on $2021 \mathrm{Jul}$ 04]

60. Wadgave U, Nagesh L. Nicotine Replacement Therapy: An overview. Int J Health Sci (Qassim) 2016;10:425-35.

61. E A Guideline on Changing the Classification for The Supply of a Medicinal Product for Human Use; 2006. Available from:https:// www.ec.europa.eu/health/sites/health/files/files/eudralex/vol2/c/ switchguide_160106_en.pdf.

62. Available from: https://www.users.ugent.be/ rvdstich/thesis/written drug_information_screen.pdf. [Last accessed on 2021 Jun 28].

63. Consulting C. 4 Tips for Making the Rx to OTC Switch. Clarkston Consulting; 2021. Available from: https://www.clarkstonconsulting. com/insights/rx-to-otc-switch-4-tips. [Last accessed on 2021 Jul 02]

64. Rx-to-OTC Switches: Growth, Drivers and the Role of Patientslubrizol; 2021. Available from: https://www.lubrizol.com/Health/ Blog/2020/11/Rx-to-OTC-Switches. [Last accessed on 2021 Jun 30].

65. Global Over-the-counter Drugs Market: Consumer Behavior Analysis by Countries, Buying Pattern Analysis, Demographics, Trends Analysis, Survey Findings and Results, Leading Companies and their Mark; 2021. Available from: https://www.markets.businessinsider.com/news/ stocks/global-over-the-counter-drugs-market-consumer-behavioranalysis-by-countries-buying-pattern-analysis-demographics-trendsanalysis-survey-findings-and-results-leading-companies-and-theirmark-1029377414. [Last accessed on 2021 Jun 28].

66. Rx-to-OTC Switches Market Analysis, Opportunities, Demand and Forecast Trends 2018-2028. Future. Available from: https://www. futuremarketinsights.com/reports/rx-to-otc-switches-market.

67. Health at a Glance: Europe 2020 State of Health in The Eu Cycle; 2021. Available from: https:/www.ec.europa.eu/health/sites/default/ files/state/docs $/ 2020$ healthatglance rep en.pdf. [Last accessed on 2021 Jul 09]

68. Global Over the Counter Drugs Market Size, Share, Trends and Growth Analysis Report-Segmented by Product Type and Region-industry 
Forecast (2021 to 2026). Maharashtra: Global Market Insights, Inc.; 2020. p. 461-75.

69. Insights on the Over-the-Counter Drugs Global Market to 2025-Growing Number of Patent Expirations Presents Opportunities Available from: https://www.globenewswire.com/news-relea se/2020/09/03/2088473/28124/en/Insights-on-the-Over-the-CounterDrugs-Global-Market-to-2025-Growing-Number-of-Patent-ExpirationsPresents-Opportunities.html [Last accessed on 2020 Sep 03].

70. Global Over-the-counter Drugs Market (2019 to 2025)-North
America Generates the Highest Revenue-research and Markets. Business; 2021. Available from: https://www.businesswire.com/news/ home/20200902005541/en/Global-Over-the-Counter-Drugs-Market2019-to-2025---North-America-Generates-the-Highest-Revenue--ResearchAndMarkets.com. [Last accessed on 2020 Sep 02].

71. Global CHC Market up 3.7\% in MAT Q3 2019 Period. Nicholas Hall Company Blog. Available from: https://www.nicholashallcompany. wordpress.com/2019/12/16/global-chc-market-up-3-7-in-mat-q32019-period. 